\title{
Psychological and Physiological Responses to Different Views through a Window in Apartment Complexes
}

\author{
Seong Min Jeon ${ }^{1}$, Minji Kang ${ }^{2}$, Su Jin Kim², Yong Jin Kim¹, Hyo Bhin Choi², and Juyoung Lee ${ }^{3 *}$ \\ ${ }^{1}$ Undergraduate student, Hankyong National University, Department of Landscape Architecture, Anseong 17579, Korea \\ ${ }^{2}$ Graduate student, Hankyong National University, Department of Landscape Architecture, Anseong 17579, Korea \\ ${ }^{3}$ Associate professor, Hankyong National University, Department of Landscape Architecture, Anseong 17579, Korea
}

\section{ABSTRACT}

Background and objective: With increasing land use intensity in urban areas, apartment buildings have been recognized as a typical type of urban residence. In this study, the impacts of different views through a window on health-related responses were investigated using psychological and physiological parameters.

Methods: Photos of three different types of views taken on low (2-12 m), middle (28-35 m), and high (over $54 \mathrm{~m}$ ) floors of dense apartment building areas were used as visual stimuli. Twenty-two healthy adults participated in the indoor experiment. Semantic differential methods and profile of mood states were used as psychological tools. Autonomic nervous activity was evaluated using blood pressures, pulse rate and heart rate variability (HRV).

Results: Analytic data showed different characteristics of psychological and physiological outcomes in three different apartment views. In the analysis of psychological parameters, significantly negative responses to the views on middle floors were found in the subscales of tension-anxiety and anger-hostility, compared to low floors. Significantly positive scores in the subscale of vigor were found on low floors with abundance of vegetation and high floors with a view of the sky. A significantly increased value of HF was found on low floors $(2,294.96 \pm 169.79)$, compared to the middle(1,553.45 \pm 84.66) and high $(1,523.02 \pm 70.49)$ floors. Despite the high scores in openness and vigor, high floor views showed significantly higher LF/HF values $(1.83 \pm 0.09)$, the indicator of the sympathetic nervous system, than low (1.30 \pm 0.07$)$ and middle floor views $(1.34 \pm 0.06)$, which might be related to the unconscious fear of heights.

Conclusion: Views from different heights in an apartment building can affect the psychological states of residents. Green space through the window may have a positive health outcome by reducing physiological stress.

Keywords: cardiovascular response, green space, health outcome, mood state, views through the window

\section{Introduction}

Population concentration into the city has been accelerated by the rapid industrialization and urbanization since the early 1960s, which led to deteriorated living environments and housing shortages (Lee et al., 1994). Thus, apartment housing complexes emerged as a new housing lifestyle as a solution for limited land use and housing shortages, and the government policy also shifted to supplying large quantities of apartments (Kang and Lee, 2004). Today, apartment housing complexes are established as a typical housing style in Korea and are taking up a critical part of building an urban structure (Lee, 2016). These complexes represented by apartments have been constructed massively in a short period of time due to its emphasis on quantitative supply, which is causing the problem of not improving the quality of exterior landscape that has a huge impact on the quality of the residential environment. In particular, the gaps

This study was funded by the Korea National Arboretum(Research project KNA 4-1-2, 19-7).

Received: September 1, 2021, Revised: September 17, 2021, Accepted: October 12, 2021

First author: Seong Min Jeon, dlwps2011@naver.com, (B) https://orcid.org/0000-0002-1067-5357

*Corresponding author: Juyoung Lee, lohawi@gmail.com, (1) https://orcid.org/0000-0002-9966-3618 
between apartment buildings are designed to be small due to intensive use of the land in urban centers, thereby not securing enough access to sunlight and view for residents.

Meanwhile, due to the increasing yearning for nature and growing demand for a pleasant life, the importance of apartment landscaping is also increasing (Shin, 2010). Apartment landscape not only affects stress relief of residents (Lee and Lee, 2018) but also has a value as a healing environment (Chun and Lee, 2016). Nonetheless, there is insufficient research on the psychological effect of green landscape in apartments on residents. Recent studies on apartment landscape mostly analyzed the use of space (Kang and Cho, 2018) or space organization (Kang, 2013). Studies were conducted on psychological response to exterior space of apartments, but they merely examined feelings toward factors of the physical environment through vocabulary assessment (Lee et al., 2000), and thus merely depended on subjective assessment of participants. Considering the importance of exterior green space in improving the residential environment in apartment complexes (Kim et al., 1998), there is insufficient research showing the characteristics of how residents perceive landscape or views. Moreover, there is a huge difference in exterior landscape depending on floors for the recently increasing high-story apartment complexes, and yet this is not sufficiently reviewed.

Therefore, the purpose of this study is to investigate the perception and psychological responses of people toward ex- terior landscape by examining high-story apartment complexes.

\section{Research Methods}

\section{Materials and stimulus presentation method}

This study obtains scientific evidence on landscape perception by measuring and analyzing it using the physiological response index to make the assessment objective. To determine the change in psychological and physiological effects due to the difference in views by height of high-rise residential facilities, we selected apartments at least 25 stories high built in the last 5 years in P city, Gyeonggi-do where there is rapid urban development. We classified buildings located relatively on the inner side of the apartment complex into low floors (1-5 floors; approximately 2-12m), middle floors (11-15 floors; approximately 28-38m), and high floors (21 floors and above; approximately $54 \mathrm{~m}$ and above) and prepared visual images by taking shots of the outside view on each floor. The photos are taken when looking at the window squarely at a horizontal angle from the inside of the apartment (Fig. 1). The experiment was conducted in a lab where temperature and humidity can be controlled, and visual images were presented in the size of $1.5 \mathrm{~m} \times 2.4 \mathrm{~m}$ that is similar to the actual landscape size through an image playback device. The photos of each floor are grouped with $10 \mathrm{im}$ -
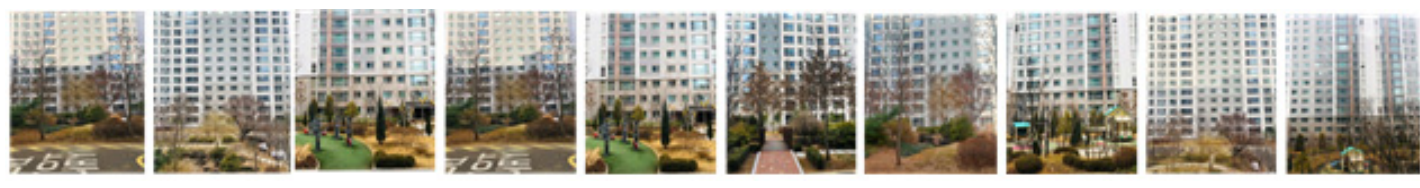

Scenery in low(1-5) floor
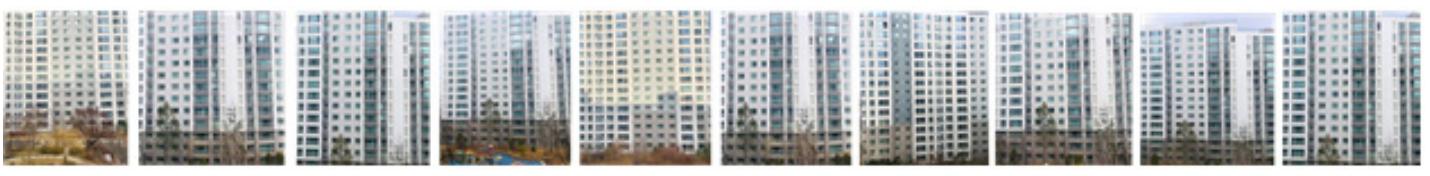

Scenery in middle(11-15) floor
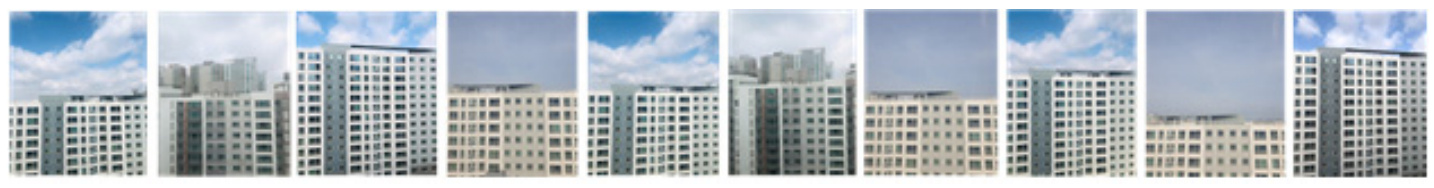

Scenery in high(21 and over) floor

Fig. 1. Three different types of visual images used in study. 
ages and presented continuously for 280 seconds, and the order of presenting the groups with different heights was random by participant to offset the order effect.

\section{Participants}

We selected 22 participants (11 male, 11 female) out of healthy men and women without any medical history such as cardiovascular or mental diseases who expressed the voluntary will to participate. We explained in detail the purpose and contents of this study before the experiment and obtained consent in writing. They were to move on a wheelchair to minimize physical movements that may affect physiological responses during the experiment. This study was approved by the Institutional Review Board (P01-202009-12-002).

\section{Measurement indicators}

To determine the difference in psychological responses depending on the difference in views by height, we used two types of psychological questionnaire to assess the impression of the landscape, change in mood states, anxiety level, etc. Semantic differential (SD) was first used to assess the impression of the difference in views by height. This study rated items using 9 symmetrical adjectives such as 'artificial-natural', 'closed-open', 'complex-simple', 'depressedlively', 'incongruous-harmonious', 'unfamiliar-friendly', 'unstablestable', 'desolate-comfortable', and 'cold-warm' on a 7-point Likert scale with reference to similar studies (Lee, 2017; Lee and Lee, 2018). The Profile of Mood States (POMS) was used to measure the change in mood states and subjective emotions depending on the view (Yeun and Shin-Park, 2006). By rating 30 items on a 5-point Likert scale, we quantified and analyzed the moods in 6 subscales such as 'tension-anxiety (T-A)', 'anger-hostility (A-H)', 'depression (D)', 'vigor (V)', 'fatigue (F)', and 'confusion (C)'.

We measured autonomic nervous system activity as an indicator of physiological responses toward the views. We measured heart rate variability (HRV) data widely used in landscape studies by sensitively reflecting the change in environmental stress. We converted R-R intervals of heart rate data into frequency and classified it into low frequency (LF) ranging from 0.04 to $0.15 \mathrm{~Hz}$ and high frequency
(HF) ranging from 0.15 to $0.40 \mathrm{~Hz}$. In general, $\mathrm{HF}$ is used as an indicator of parasympathetic nervous system activation, and $\mathrm{LF} / \mathrm{HF}$ as an indicator of sympathetic nervous system activation (Task Force of the European Society of Cardiology and the North American Society of Pacing and Electrophysiology, 1996). HRV was continuously measured while the participants looked at the visual images and recorded using Mybeat (UNION TOOL Co., Japan). We also measured blood pressure and pulse rate as the typical indicators of autonomic nervous system activity, which we measured 2-3 times on the upper right arm using a sphygmomanometer HEM-1000 (OMRON, Japan) after looking at the views, and recorded the means.

\section{Data analysis}

We analyzed the response characteristics toward each view by comparing the values that quantified psychological and physiological indicators when looking at different views on different heights. A statistical test was conducted using SPSS Statistics 21.0 (IBM, USA) on physiological and psychological data of all participants. A Kruskal-Wallis test was used to analyze psychological data, and a paired samples t-test to analyze physiological data. One-way analysis of variance (ANOVA) was used to compare the responses toward different views by height at high-rise residential facilities. The results were presented in mean \pm standard error, and the statistical significance level was set at $p<.05$.

\section{Results and Discussion}

\section{Analysis of psychological landscape perception}

As a result of analyzing the impression evaluation on the difference in views by height of high-rise apartments, there was a significant difference in 8 out of total 9 items excluding 'complex-simple' (Fig. 2). Overall, naturality $(0.77 \pm$ $0.24)$ and openness $(0.41 \pm 0.32)$ were high in low floor views of green space outside, and openness $(0.45 \pm 0.33)$ and stability $(0.45 \pm 0.23)$ were relatively high in high floor views. Spatial openness of an apartment complex is greatly affected by the height of the housing (Kang and Park, 2006), which is why low-rise buildings were expected to seem more closed compared to mid-rise or high-rise build- 
ings, but they actually showed a similar level of openness as high floor views. A previous study (Kim et al., 2021) reported that people may feel greater spatial openness when there are plants even if the size of the space is the same. The psychological response shown in this experiment can be interpreted in this context. On the contrary, middle floor views that mostly show the apartment building on the other side showed a remarkable increase in coldness $(-1.41 \pm 0.28)$ and closedness $(-1.18 \pm 0.31)$, generally showing negative responses.

As a result of POMS data analysis on landscape, middle floor views with high closedness showed remarkably high negative mood states such as tension-anxiety (T-A; $4.71 \pm$ 0.97 ), hostility (A-H; $2.63 \pm 0.69$ ), and confusion (C; $5.46 \pm$ 0.90) (Fig. 3). On the other hand, these negative emotions were remarkably low in low floor views (T-A, $2.33 \pm 0.71$; $\mathrm{A}-\mathrm{H}, 0.92 \pm 0.40$; C, $3.50 \pm 0.75)$, while vigor $(\mathrm{V}, 7.04 \pm 1.00$ ) increased significantly. In high floor views showing the sky, vigor $(\mathrm{V}, 5.58 \pm 0.98)$ was also higher than middle floor views. This result implies that apartment landscape may constantly affect the psychological state of residents, and it

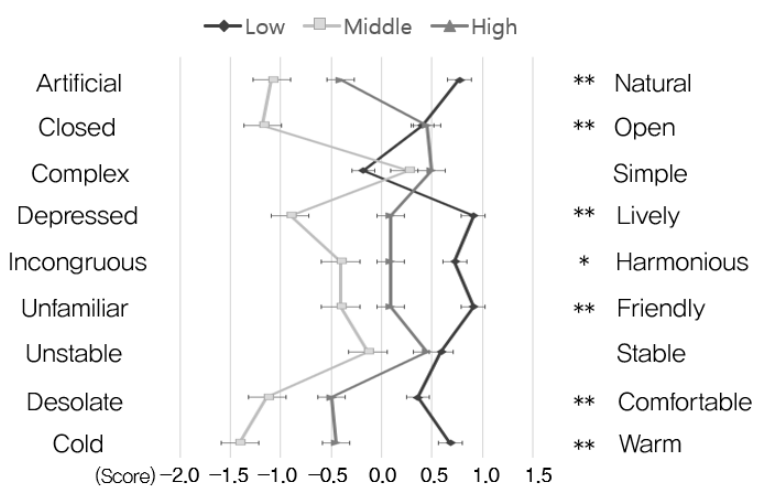

Fig. 2. Analysis of SD values in three different kinds of landscapes.

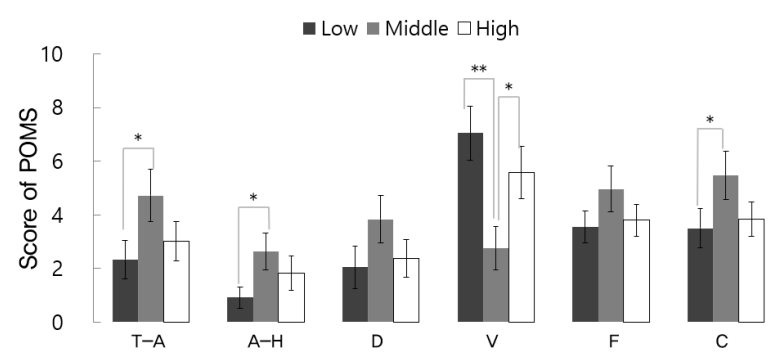

Fig. 3. Analysis of POMS scores in three different kinds of landscapes. partially supports the fact that children living on middle floors exposed to this closed and stuffy landscape are showing a relatively high disease incidence (Choi and Kang, 2001). Indoor green space in apartments reduces spatial closedness felt by residents and has a positive effect on changes in their emotions and mood states (Hung and Chang, 2021), and thus it can be used as a means to solve health problems caused by the environment.

\section{Responses to views from the physiological perspective}

As a result of analyzing HRV data when looking at the views, it was found that the physiological responses of participants varied depending on the landscape. HF, which is the indicator of parasympathetic nervous system activity, showed higher means in low floors $(2,294.96 \pm 169.79$; Fig. 4) compared to middle floors $(1,553.45 \pm 84.66 ; p<.01)$ and high floors $(1,523.02 \pm 70.49 ; p<.01)$, showing a statistically significant difference. LF/HF, which is the indicator of the sympathetic nervous system increased in tension, showed significantly lower means in low floors $(1.30 \pm 0.07$; $p<.01)$ and middle floors $(1.34 \pm 0.06 ; p<.01)$ compared to high floors $(1.83 \pm 0.09$; Fig. 5). The results of analyzing systolic blood pressure (low floors, $112.05 \pm 2.90$; high floors, $116.67 \pm 3.12 ; p<.01$; Fig. 6) and pulse rate(low floors, $70.05 \pm 2.02$; high floors, $71.18 \pm 2.05 ; p<.05$; Fig. 7) also showed significantly lower means in low floor than high floor views. This indicates that residents have lowest physiological stress, by which they are unconsciously affected, on low floor views where they can see the landscape, which is because green space resolves psychological tension and reduces physiological stress (Herzog et al., 1997; Roe et al., 2013; Shin and Shin, 2020). A preference survey on apartment views also proved that people preferred low-rise apartments with a higher ratio of natural landscapes than mid-rise apartments (Moon et al., 2006), and this result clearly shows the psychological response that explains the difference in landscape preference. The interesting thing is that high floor views tended to inhibit parasympathetic nervous system activity and accelerate sympathetic nervous system activity, which indicates that high floor views may unconsciously have a negative impact on psychological health. A study on high-rise settings also showed similar 


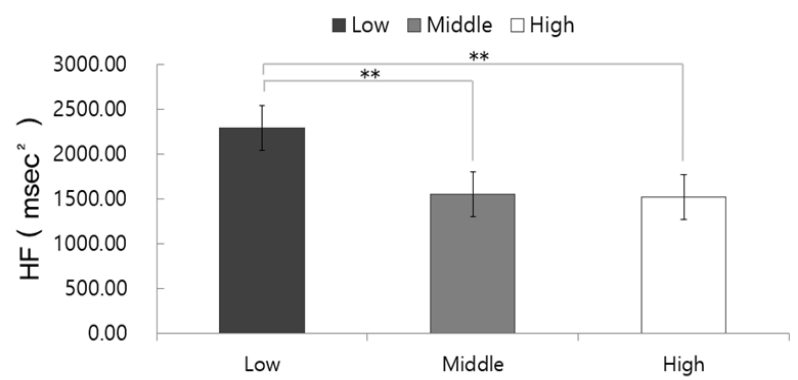

Fig. 4. Analysis of HF power of HRV in three different kinds of landscapes.

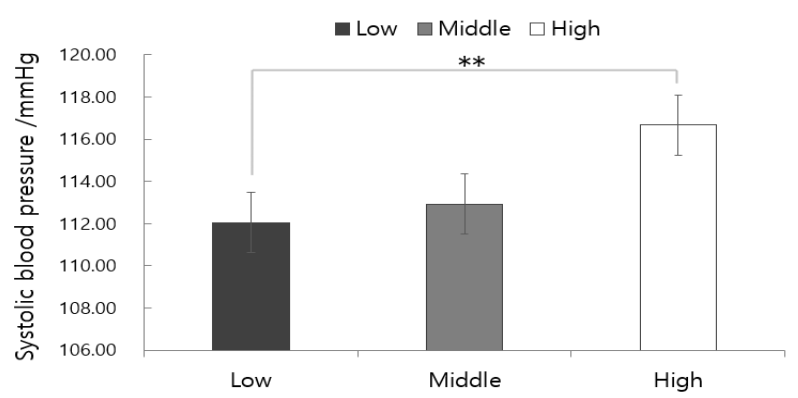

Fig. 6. Analysis of Systolic blood pressure in three different kinds of landscapes.

results as this study (Kim and Ha, 1996). Views from high floors induce fear and anxiety and simulate the sympathetic nervous system, thereby increasing blood pressure. With the growing concerns of health due to the increase in high-rise residential environment (Kang and Choi, 2008), this study proves that landscape or views may be a direct factor that affects resident health.

\section{Conclusion}

High-rise apartments today have various issues regarding views, and this study quantitatively compared and analyzed the effect of landscape or views in terms of psychological and physiological aspects of residents. There was a clear difference in the results of analyzing psychological and physiological responses to views on different floors. The result was most positive in the stability of autonomic nerves due to alleviated negative psychological state and activation of the parasympathetic nervous system on low-rise apartments. Today, apartment consumers tend to prefer a high-rise,

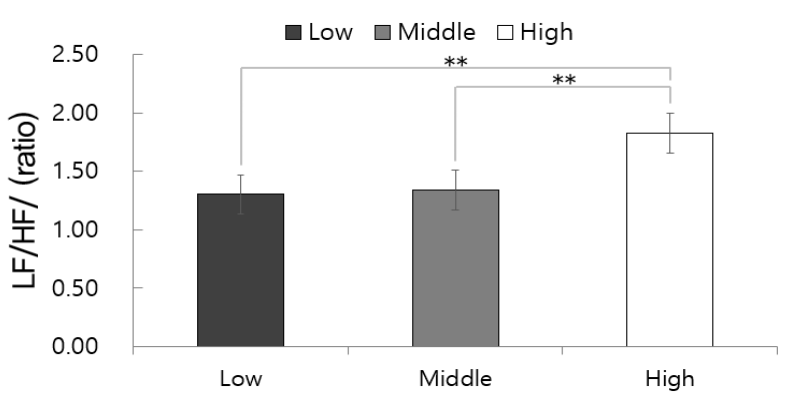

Fig. 5. Analysis of LF/HF ratio of HRV in three different kinds of landscapes.

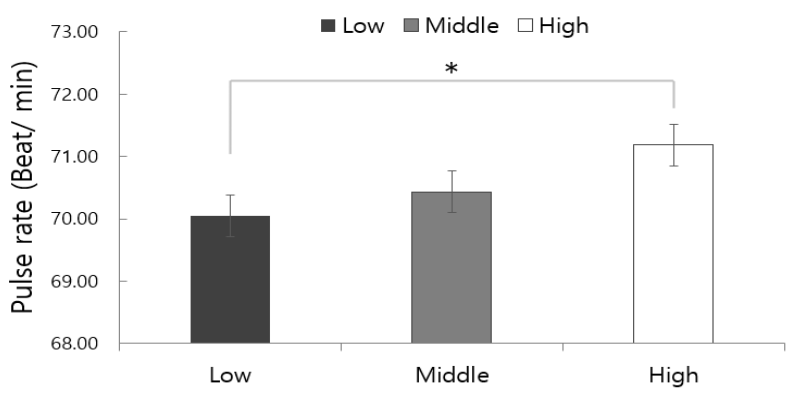

Fig. 7. Analysis of Pulse rate in three different kinds of landscapes.

open view (Lee and Kim, 2014), but high floor views with limited vision may rather increase physiological stress. Apartment views have a direct impact on resident health and quality of life, and there is a need for technical and systematic review to secure the right to a high-quality view in apartment complexes that are becoming more densified and higher. This study has limitations in that the age of the participants is limited to the $20 \mathrm{~s}$, and the landscape images used in the experiment do not fully reflect the characteristics of high-rise apartments in Korea. Various studies must be conducted in the future to determine the correlation between apartment views and health.

\section{References}

Choi, B.S. and I.H. Kang. 2001. An empirical research on the high-rise dwelling and the disease patterns of the children based on the medical records of A-university hospital. J. Archit. Inst. Korea Plan. Des. 17(5):51-60.

Chun, H. and S. Lee. 2016. A study on the design guidelines 
of healing landscape in housing complexes. J. Korea Inst. Landsc. Archit. 44(5):26-37. https://doi.org/10.971 5/KILA.2016.44.5.026

Herzog, T.R., A.M. Black, K.A. Fountaine, and D.J. Knotts. 1997. Reflection and attentional recovery as distinctive benefits of restorative environments. J. Environ. Psychol. 17(2):165-170. https://doi.org/10.1006/jevp.1997.0051

Hung, S.H. and C.Y. Chang. 2021. Health benefits of evidencebased biophilic-designed environments: A review. J. People Plants Environ. 24(1):1-16. https://doi.org/10.11628/ksp pe.2021.24.1.1

Kang, I.H. and B.S. Choi. 2008. Contents analysis on medical reports of high-rise condominium residents. J. Korean Hous. Assoc. 19:57-65.

Kang, L.H. and J.K. Lee. 2004. A study on landscape satisfaction in an apartment complex and an improvement plan-Focus on the surveys targeting the residents in apartment complexes. Ind. Sci. Res. 15:1-11.

Kang, I.H. and S.Y. Park. 2006. A study on th design characteristics of court housing in case study on the competition entries of Eunpyung newtown. J. Korean Hous. Assoc. 17(5):107-116.

Kang, S.W. and S.H. Cho. 2018. Analysis of resident's consciousness by using of landscape area as urban parks and green spaces in apartment complex - with special reference to the city of Seoul in Korea. Rev. Bio-Tech. Landsc. Urban. 3(1):1-9.

Kang, Y.J. 2013. Changes and characteristics of landscape architectural design in Korean apartment housing - focused on apartment housing complexes in metropolitan area. Doctoral dissertation, Seoul National University, Seoul, Korea.

Kim, N.G. and J.M. Ha. 1996. A study on psychological and physiological effects of fear of being off ground in superhigh rise apartment. J. Archit. Inst. Korea 12(8):37-41.

Kim, E.I., J.S. Baik, and S.C. Suh. 1998. Comparison of sightpsychological effect of open and closed landscape on open spaces. J. Korean Soc. People Plants Environ. 1(1):88-95.

Kim, S.J., MK. Kang, and J. Lee. 2021. Verification of physiological and psychological effects of vertical indoor garden. J. Environ. Sci. Int. 30(1):1-10. https://doi.org/10.5322/JE SI.2021.30.1.1

Lee, D.H. 2016. An analysis of the residents' landscape psy- chology with special reference to apartment complex. Master's thesis, Hanyang University, Seoul, Korea.

Lee, J. 2017. Experimental study on the health benefits of garden landscape. Int. J. Environ. Res. Public Health 14(7): 829. https://doi.org/10.3390/ijerph14070829

Lee, J.S. and J.H. Kim. 2014. The impacts of environment attributes of the apartment on consumer preference: A conjoint analysis with view quality and park accessibility. J. Mark. Manag. Res. 19(2):91-109.

Lee, K.C., H.T. Lee, and D.P. Kim. 1994. A study on the management condition of exterior space in APT. complex - in the case of Gisan APT. complex in Daegu. J. Korea Inst. Landsc. Archit. 22(3):121-135.

Lee, Y.H. and K.K Lee. 2018. An analysis of the elements of landscape space in apartment influencing to reduce stress. J. Korea Real Estate Soc. 36(2):97-109.

Lee, Y.J., J.H. Jeong, and J.W. Lhee. 2000. A study on the psychological characteristics of exterior environment in apartment housing estates. J. Archit. Inst. Korea Plan. Des. 16(12):117-124.

Moon, J.W., S.B. Lee, and J.M. Ha. 2006. Preference of th view from apartment units regarding view points. Proceedings of Korea Hous. Assoc. Fall conference. (pp. 242-247).

Roe, J.J., C.W. Thompson, P.A. Aspinall, M.J. Brewer, E.I. Duff, D. Miller, R. Mitchell, and A. Clow. 2013. Green space and stress: Evidence from cortisol measures in deprived urban communities. Int. J. Environ. Res. Public Health 10(9):4086-4103. https://doi.org/10.3390/ijerph1 0094086

Shin, K.J. 2010. The tansition of outdoor space and periodical characteristics of landscaping in Korean apartment housing. Doctoral dissertation, Dankook University, Seoul, Korea.

Shin, J.Y. and W.S. Shin. 2020. Effects of nature-based programs for workers in Korea: A review. J. People Plants Environ. 23(2):125-138. https://doi.org/10.11628/ksppe.2020.23.2.125

Marek, M. 1996. Heart rate variability: standards of measurement, physiological interpretation and clinical use. Circulation 93(5):1043-1065. https://doi.org/10.1161/01.CIR.93.5.1043

Yeun, E.J. and K.K.B Shin-Park. 2006. Verification of the profile of mood states-brief: Cross-cultural analysis. J. Clin. Psychol. 62(9):1173-1180. https://doi.org/10.1002/ jclp.20269 